\title{
Correction to: “Cooperativity Between Zirconium Dioxide Nanoparticles and Extreme Pressure Additives in Forming Protective Tribofilms: Toward Enabling Low Viscosity Lubricants"
}

\author{
Meagan B. Elinski ${ }^{1}$ (D) Parker LaMascus ${ }^{1}$ (I) $\cdot$ Lei Zheng $^{2} \cdot$ Andrew Jackson $^{1} \cdot$ Robert J. Wiacek $^{2} \cdot$ Robert W. Carpick $^{1}(\mathbb{D}$
}

Published online: 23 September 2021

○ Springer Science+Business Media, LLC, part of Springer Nature 2021

\section{Correction to: Tribol Lett (2020) 68:107 https://doi.org/10.1007/s11249-020-01346-1}

The SLIM technique reported in this work uses an RGB optical signal to calculate in situ tribofilm thickness. Due to a firmware error in the Spacer Layer Interference Method (SLIM) camera of the Mini-Traction Machine (MTM) used by the authors, the output data of the SLIM system contained an oversaturated blue signal, leading to incorrect film heights in the SLIM system (Fig. 2g).

In the course of correcting reported SLIM data with a new, correctly calibrated camera, the authors discovered an error in the White Light Interferometer (WLI), which had originally been obfuscated by the SLIM error: oil residue on the MTM samples led to artifacts in measurements of tribofilm step-edge heights. WLI data obtained after using a modified cleaning procedure avoided this artifact. This WLI artifact changes the morphologies of reported data which contain $\mathrm{ZrO}_{2}$ (Figs. 3, 4) and the estimated wear of the MTM specimens (Fig. 8). Figures 6 and 7 concern control specimens without $\mathrm{ZrO}_{2}$, and are therefore unaffected by the viscous oil error.
Though the corrected tribofilm heights and step edges were systematically less than the originally published values, the conclusions of the original work are unchanged. Zirconia tribofilms formed in fully formulated $75 \mathrm{~W}-80$ gear oils led to significantly less wear of the steel substrate compared with films formed in neat polyalphaolefins, suggesting cooperation between $\mathrm{ZrO}_{2}$ and the $\mathrm{P} / \mathrm{S}$ containing co-additives of the gear oil.

Accordingly, the following corrections are warranted.

1. The Abstract should be corrected as follows:

Original text: "The results show that $\mathrm{ZrO}_{2}$ NPs reproducibly develop surface-bound $100 \mathrm{~nm}$ thick tribofilms on both contacting surfaces under a wide range of rolling-sliding contact conditions, from 0 to $100 \%$ slide-toroll ratio".

Corrected text (corrections indicated in underlined italics): "The results show that $\mathrm{ZrO}_{2}$ NPs reproducibly develop surface-bound $\sim 20-60 \mathrm{~nm}$ thick tribofilms on both contacting surfaces under a wide range of rolling-

The original article can be found online at https://doi.org/10.1007/ s11249-020-01346-1.

Robert W. Carpick

carpick@seas.upenn.edu

1 Department of Mechanical Engineering \& Applied Mechanics, University of Pennsylvania, Philadelphia, PA 19104, USA

2 Pixelligent Technologies LLC, Baltimore, MD 21224, USA 
sliding contact conditions, from 0 to $100 \%$ slide-to-roll ratio".

2. The cleaning procedure for the MTM specimens on page 5 of 17 should be changed as follows:

Original text: "A Cressington Sputter Coater 108 was used to coat the test specimens using a Au/Pd target."

Corrected text (added text in underlined italics), "Prior to coating. samples were sonicated in toluene followed by 2-propanol, and then a Cressington Sputter Coater 108 was used to coat the test specimens using a $\mathrm{Au} / \mathrm{Pd}$ target".

3. On page 8 of 17 , the discussion of film thickness should be corrected as follows:

Original text: "These films were thinnest for $\mathrm{ZrO}_{2}+75 \mathrm{~W}-80$, but in general ranged from 100 to $120 \mathrm{~nm}$. The exception to the $100-120 \mathrm{~nm}$ tribofilm thickness is for $\mathrm{ZrO}_{2}+75 \mathrm{~W}-80$ at a $\%$ SRR, which only forms a $13 \pm 10 \mathrm{~nm}$ thick tribofilm".

Corrected text (corrections indicated in underlined italics): "These films were thinnest for $\mathrm{ZrO}_{2}+75 \mathrm{~W}-80$, but in general ranged from 30 to $60 \mathrm{~nm}$. The exception to the $\underline{30-60 \mathrm{~nm}}$ tribofilm thickness is for $\mathrm{ZrO}_{2}+75 \mathrm{~W}$ 80 at a $0 \%$ SRR, which only forms a $\underline{17 \pm 6 \mathrm{~nm}}$ thick tribofilm".

4. On page 14 of 17 , this sentence should be omitted as it is no longer relevant: "This difference is particularly pronounced for the $\mathrm{ZrO}_{2}+\mathrm{PAO} 4$ film, with a $115 \mathrm{~nm}$ thick film measured in SLIM and approximately a $250 \mathrm{~nm}$ thick film measured in SIMS".
5. On page 14 of 17 , the following sentences should be omitted as they are no longer relevant: "The influence of a roughened interface on the apparent depth is qualitatively supported by comparison to the $\mathrm{ZrO}_{2}$ tribofilm formed in $75 \mathrm{~W}-80$. The $\mathrm{ZrO}_{2}+75 \mathrm{~W}-80$ films typically have a less striated surface morphology, with less underlying wear, and there is correspondingly improved agreement between the film thickness measured by SLIM (90 nm) and the SIMS depth profiling (125 nm)."

6. The corrected version of Figs. 2(g), 3, 4, and 8 are below.

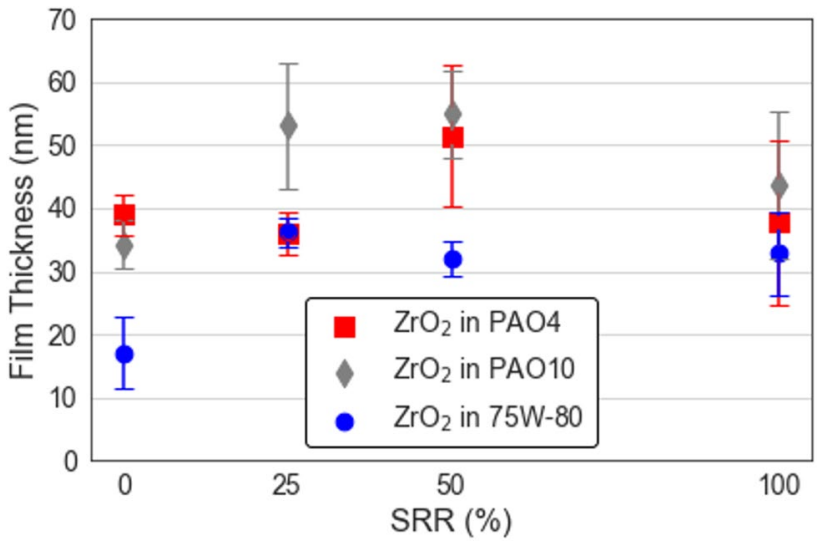

Fig. 2 (g) End-of-test ball tribofilm thicknesses measured by the MTM-SLIM system 
(a) $\mathrm{ZrO}_{2}+\mathrm{PAO} 4$ @ 0\% SRR

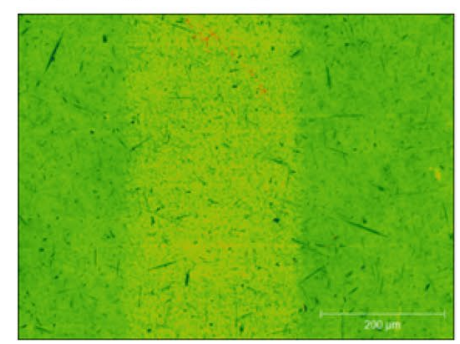

(d) $\mathrm{ZrO}_{2}+\mathrm{PAO} 4$ @ $25 \% \mathrm{SRR}$

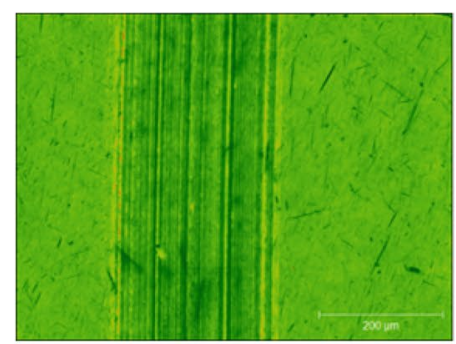

(g) $\mathrm{ZrO}_{2}+\mathrm{PAO} 4 @ 50 \% \mathrm{SRR}$

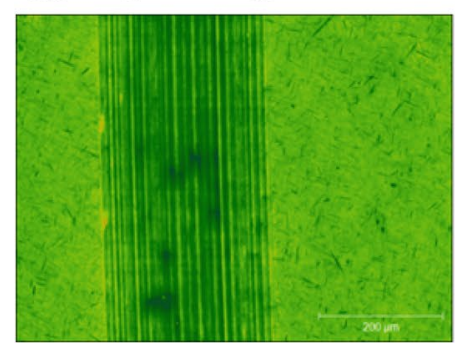

(j) $\mathrm{ZrO}_{2}+\mathrm{PAO} 4$ @ $100 \% \mathrm{SRR}$

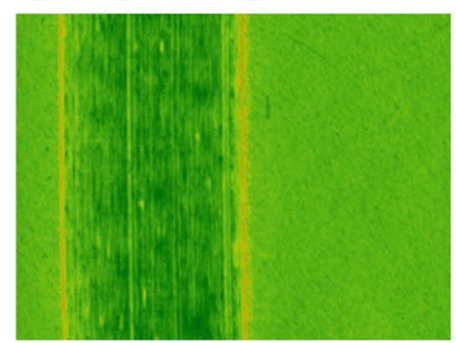

(b) $\mathrm{ZrO}_{2}+\mathrm{PAO} 10 @ 0 \% \mathrm{SRR}$

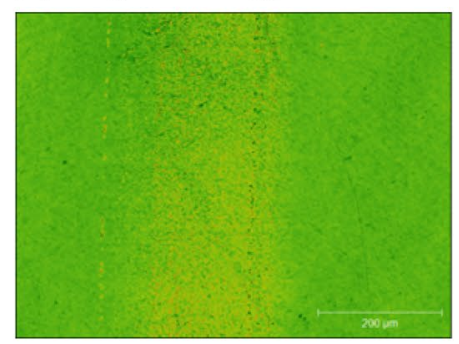

(e) $\mathrm{ZrO}_{2}+\mathrm{PAO} 10 @ 25 \% \mathrm{SRR}$

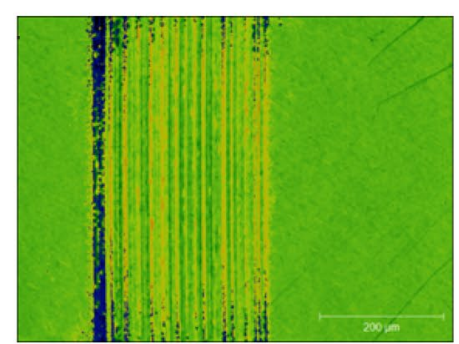

(h) $\mathrm{ZrO}_{2}+\mathrm{PAO} 10 @ 50 \% \mathrm{SRR}$

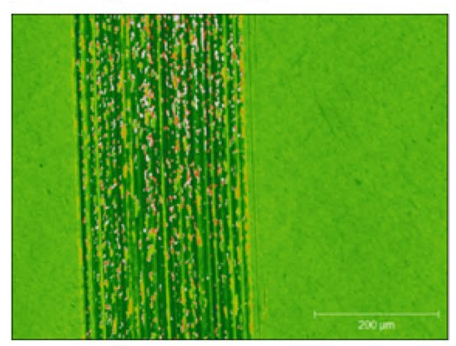

(k) $\mathrm{ZrO}_{2}+\mathrm{PAO} 10 @ 100 \% \mathrm{SRR}$

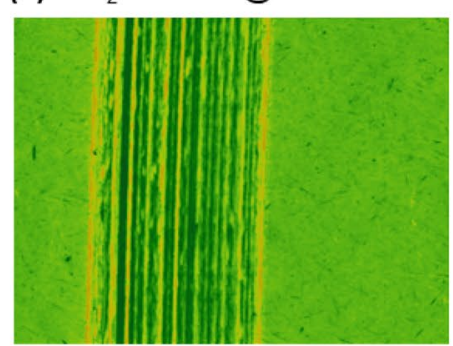

(c) $\mathrm{ZrO}_{2}+75 \mathrm{~W}-80 @ 0 \%$ SRR

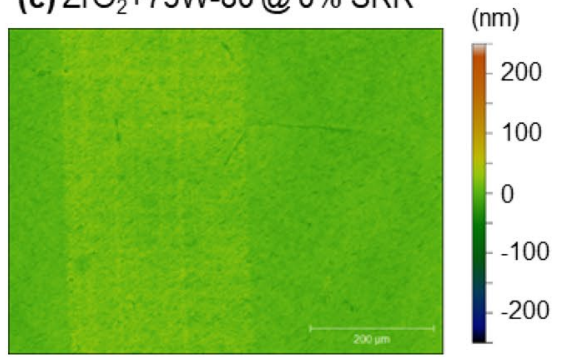

(f) $\mathrm{ZrO}_{2}+75 \mathrm{~W}-80 @ 25 \% \mathrm{SRR}$

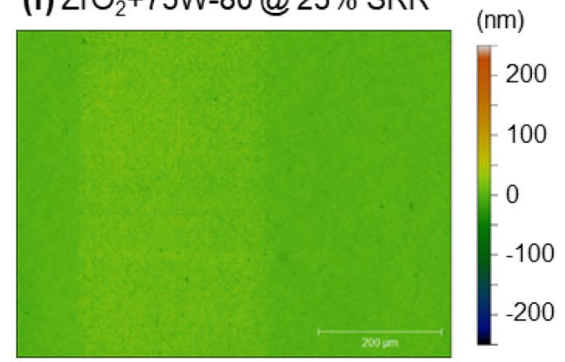

(i) $\mathrm{ZrO}_{2}+75 \mathrm{~W}-80 @ 50 \% \mathrm{SRR}$

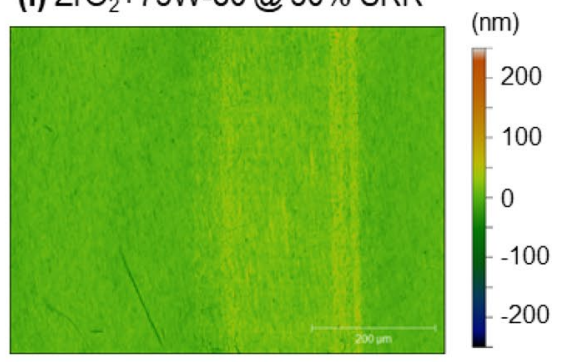

(I) $\mathrm{ZrO}_{2}+75 \mathrm{~W}-80 @ 100 \% \mathrm{SRR}$

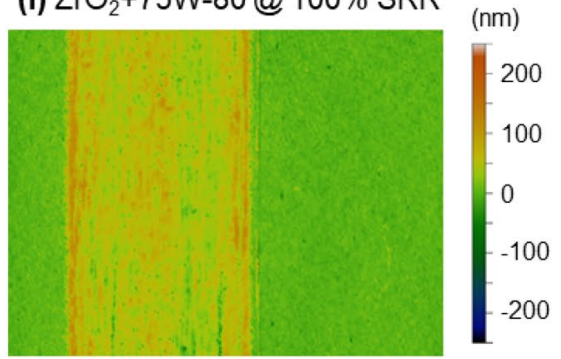

Fig. 3 White light interferometry (WLI) images (700 $\mu \mathrm{m} \times 530 \mu \mathrm{m}, \pm 250 \mathrm{~nm} \mathrm{z}$-scale), corrected for spherical curvature, for AuPd-coated MTM ball specimens after MTM tests conducted for $2 \mathrm{~h}$ at $100{ }^{\circ} \mathrm{C}, 1.12 \mathrm{GPa}$, and $150 \mathrm{~mm} / \mathrm{s}$ entrainment speed.
Images a-c show the tribofilms formed at $0 \% \mathrm{SRR}$ for $\mathrm{ZrO}_{2}+\mathrm{PAO} 4$, $\mathrm{ZrO}_{2}+\mathrm{PAO} 10$, and $\mathrm{ZrO}_{2}+75 \mathrm{~W}-80$, respectively. Similarly, $\mathbf{d}-\mathbf{f}$ show the $25 \%$ SRR trials, $\mathbf{g}-\mathbf{i}$ show the $50 \%$ SRR trials, and $\mathbf{j}-\mathbf{l}$ show the $100 \%$ SRR trials 
Fig. 4 3D projections of the WLI images (corrected for spherical curvature) shown in Fig. 3j,k,l for tribofilms formed at $100 \%$ SRR: $\mathbf{a} \mathrm{ZrO}_{2}+\mathrm{PAO} 4$, b $\mathrm{ZrO}_{2}+\mathrm{PAO} 10$, and $\mathbf{c}$ $\mathrm{ZrO}_{2}+75 \mathrm{~W}-80$. The colored lines in $\mathbf{a}-\mathbf{c}$ indicate the cross sections taken for a 50-line average, overlaid in $\mathbf{d}$ with red for $\mathrm{ZrO}_{2}+\mathrm{PAO} 4$, gray for $\mathrm{ZrO}_{2}+\mathrm{PAO} 10$, and blue for $\mathrm{ZrO}_{2}+75 \mathrm{~W}-80$

(a)

PAO4

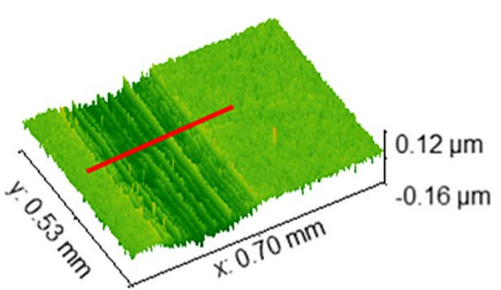

(c)

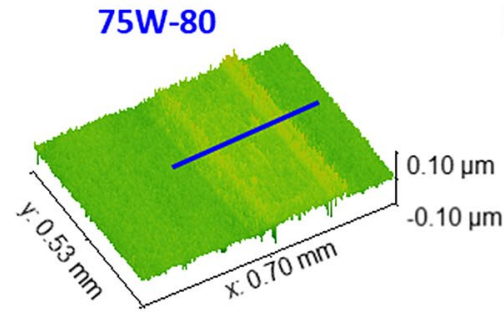

(b)

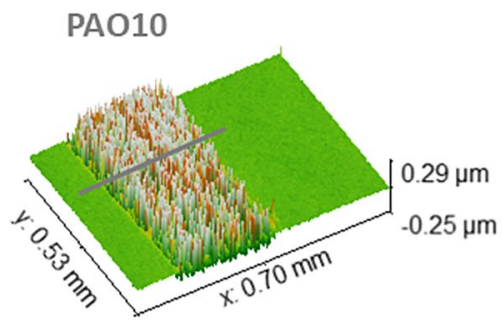

(d)

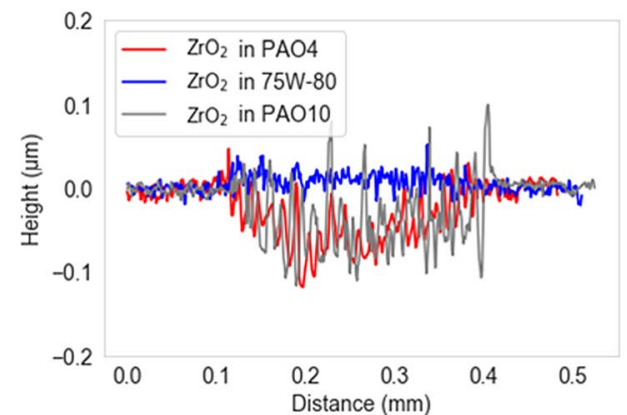

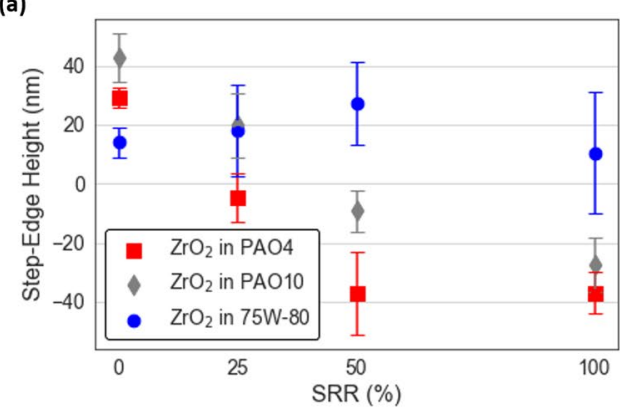

Fig. 8 The average tribofilm step-edge height for each sample/SRR shown in Fig. 3 is plotted in (a), where $\mathrm{ZrO}_{2}+\mathrm{PAO} 4$ is red squares, $\mathrm{ZrO}_{2}+\mathrm{PAO} 10$ is gray diamonds, and $\mathrm{ZrO}_{2}+75 \mathrm{~W}-80$ is blue circles. Using the difference from the tribofilm thicknesses measured in

Publisher's Note Springer Nature remains neutral with regard to jurisdictional claims in published maps and institutional affiliations. (b)

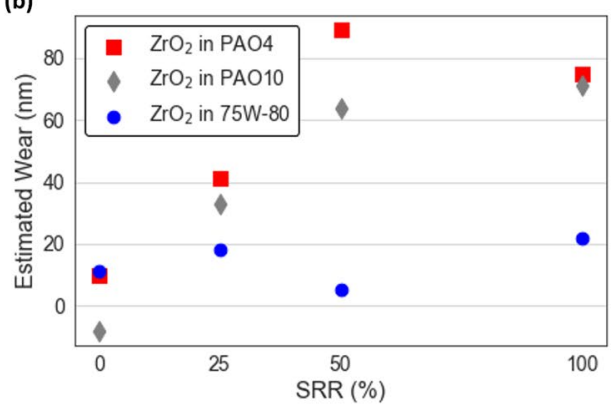

SLIM and the step-edge heights measured in WLI, b plots the estimated wear depths as a function of SRR $\left(\mathrm{ZrO}_{2}+\mathrm{PAO} 4\right.$ is red squares, $\mathrm{ZrO}_{2}+\mathrm{PAO} 10$ is gray diamonds, and $\mathrm{ZrO}_{2}+75 \mathrm{~W}-80$ is blue circles) 